\title{
BLAS INFANTE, LA CASA DE LA ALEGRÍA RECUPERADA
}

Víctor Pérez Escolano

Departamento de Historia, Teoria y Composición Arquitectónicas, U. de Sevilla

La Casa de la Alegría ya es la Casa de Blas Infante. La idea de una casa sencilla, sin arquitecto, casi popular, construida para el gozo de la vida familiar, deviene compleja en su elaboración decorativa, pues queriendo representar a Andalucia, se hace visionariamente retrospectiva, conformando el escenario y parte de una misión política, otra entre las florecidas en los años de la Segunda República, frustradas dramáticamente con el levantamiento militar y faccioso que encontró en el notario de Coria la presa perfecta para su inmolación en el inmenso altar de sacrificio humano en que convirtieron a España. Los breves años republicanos fueron los de la alegria de aquel lugar arcádico levantado en el altozano abierto sobre el río grande de Andalucía, entre Coria y Puebla, en la linde acuática de la primitiva geografia, locus primigenio. Fluyeron aquellos años como un hondo y breve suspiro, dando paso a décadas de tristeza en la casa del dolor y de la ausencia. Pero, con su memoria desvelada, extendida junto al sentimiento de la tierra y la libertad, el rescate de la democracia trajo el despertar de su condición de patrimonio colectivo. Así, la Casa de la Alegría recuperada lo es ya para todos los andaluces, la Casa de Blas Infante.

El ideal andaluz de Blas Infante adquiere un extraordinario relieve en el proceso de la construcción de la España de las Autonomías que consagra la Constitución de 1978, y se culmina mediante su reconocimiento como "padre de la patria andaluza" que le otorga el Estatuto de Autonomía. Su especial contribución doctrinal y su dramática muerte son dos factores decisivos en la aceptación general de su figura, pero también el reconocimiento del significado memorial de los lugares vinculados a su vida y su muerte: su casa natal en Casares; el lugar del kilómetro 4 de la carretera a Carmona donde se le asesinó vilmente y ahora se levanta en su recuerdo un monumento de dudoso gusto; y su hogar en Coria, la "Casa" corazón del recinto dedicado a la autonomía, museo y centro de investigación, levantado por la Junta de Andalucia.
El último eslabón ha sido esta intervención en la vivienda que fuera de Blas Infante, una vez completada su titularidad autonómica. El visitante, traspasando el vestíbulo del Museo de la Autonomía, hace un ameno recorrido por un camino latericio, disfrutando de los jardines, y alcanzando la cota más alta donde aparece la singular casa. Imagen curiosa de construcción de albañilería vista rematada de almenas, respondiendo al propósito de hacer hermética una construcción entonces aislada en el campo. Un encastillamiento relativo, pues no deja de ser una casa de pueblo, de puerta y dos ventanas, alargada con su parte de atrás encalada. Casi dos casas unidas, cada una con su puerta, delante y a un lado, distinción que dentro se hace aún más radical. En la primera casa, un interior en penumbra, ahora más acusada, cuajada de decoración cerámica en suelo y paredes rematadas con yeserias, portajes y techos de madera, y pinturas murales, el espacio creado manifiesta intensamente la acumulación de un universo de referencias en una sintesis imposible del sueño andaluz. Pasando a la segunda casa, tras la escalera y la puerta misteriosa, la sobrecarga formal se aligera y el hogar se muestra más luminoso, gracias a un pequeño patio, como corresponde a la vida doméstica. Detrás de todo, estuvieron los informales y caracteristicos complementos rurales.

No era nada fácil encarar la intervención restauradora y musealizadora de la casa de Blas Infante. El trabajo arquitectónico proyectado por Antonio Tejedor ha consistido en poner en su justo valor una casa tan singular, dada su escasa densidad constructiva, tectónica y espacial. La decisión de partida fue correcta. La casa de Infante, restaurarla tal cual era, con todos los atributos decorativos, muebles y objetos elegidos por Infante según el gusto de la época propios del regionalismo dominante. Pero, tras la segunda, las adiciones existentes han mutado sutilmente, reconvirtiéndose según las necesidades que su carácter institucional reclamaba, en particular el Aula Blas Infante, donde la visita debería rendir re- flexión y fruto. Asi, una tercera casa, limpia y lista para cumplir su misión pedagógica e investigadora, ha sido ahora proyectada. Un espacio pensado para abrirse y ofrecer un nuevo panorama del lugar, cuando en el ámbito de llegada, el paisaje natural originario, con el río ofreciéndose, se ha perdido definitivamente por la urbanización sin orden ni concierto que ha arrasado la percepción rural que Blas Infante eligió.

¿No hubiese bastado con ese complemento propedéutico para ilustrar al visitante y dejar la casa propiamente dicha como tal? Se optó por "museografiarla" según la instalación hecha por Bico Bermúdez, enrareciendo inevitablemente las estancias domésticas. Una vez más, se hace evidente la difícil conciliación entre restauración e instalación cuando a las pequeñas arquitecturas se les quiere introducir contenidos expositivos. Mantengo la opinión de que un edificio con valores patrimoniales muy determinados, especialmente las casas familiares de personajes relevantes, deben mostrarse tal cual fueron, o con el aspecto más próximo que sea posible a su carácter doméstico, a fin de ofrecer el cabal escenario privado de la figura que lo habitó. Máxime cuando se trata de una casa, como la de Blas Infante, cuyos valores históricos son el exclusivo fundamento de su conservación, pues hay que convenir que si la Casa de la Alegría lo hubiese sido de un anónimo ciudadano, careceria del singular reconocimiento patrimonial que se le ha otorgado. 